\title{
Simultaneous Removal of Trichloroethylene and Hexavalent Chromium in Groundwater by Iron Powder
}

\author{
Yanjiao Gao ${ }^{a}$, Rui Liu ${ }^{\mathrm{b}}$ \\ ${ }^{1}$ School of Civil and Architectural Engineering, Liaoning University of Technology, Jinzhou 121001, \\ China \\ ayanjiaogao@163.com, b18547587505@163.com
}

\begin{abstract}
Keywords: hexavalent chromium; trichloroethylene; groundwater; iron powder
Abstract. In order to investigate simultaneously removing effect of iron powder $(\mathrm{Fe}(0))$ on trichloroethylene (TCE) and hexavalent chromium $(\mathrm{Cr}(\mathrm{VI}))$, $\mathrm{Fe}(0)$ was used to treat $\mathrm{TCE}$ and $\mathrm{Cr}(\mathrm{VI})$ of polluted groundwater at room temperature and Features on the surface of $\mathrm{Fe}(0)$ surface were checked by Scanning Electron Microscopy (SEM) and Energy-Dispersive Spectrometry. The experimental results showed that the iron powder could simultaneously remove the TCE and $\mathrm{Cr}(\mathrm{VI})$ in the groundwater, and achieved good removal rate. After 200 days, the largest removal rate of $94.8 \%$ was reached for TCE and $96.4 \%$ for Cr(VI). Through analysis of the images of SEM and EDS a conclusion was acquired that the iron powder surface contained the elements of carbon, oxygen, silicon, calcium, chromium and iron.
\end{abstract}

\section{Introduction}

Hexavalent chromium (Cr(VI)) and trichloroethylene (TCE) are two kinds of common contaminants found in polluted groundwater.Excessive $\mathrm{Cr}(\mathrm{VI})$ has a lethal effect on aquatic organisms and experiments showed that the contaminated drinking water of $\mathrm{Cr}(\mathrm{VI})$ can cause cancer. TCE is cumulative anesthetics of central nervous system and it hurts liver, kidney and heart. Because of the dangers of $\mathrm{Cr}(\mathrm{VI})$ and TCE on the environment some economic and effective methods must be used to deal with them. Pump and treat technologies and in situ remediation technologies are two broad approaches[1]. Pump and treat technologies has a few shortcomings: difficult to remove contaminants thoroughly; limited influence radius of drawn wells groups; should not be used for poor permeability or NAPL (Non Aqueous Phase Liquids) aquifer[2]. In situ repair included electric repair, bioremediation and chemical remediation[3]. PRB (Permeable Reactive Barrier) is a common device to process pollutants in the groundwater[4]. The packing of PRB included iron powder, activated carbon, zeolite and biological materials which could remove pollutants through adsorption, chemical precipitation, oxidation reduction and biochemical reaction[5-7]. Commonly used material was cheap iron, iron could effective adsorb and decrease a variety of heavy metals and organic matters. The use of $\mathrm{Fe}(0)-\mathrm{PRBs}$ for treating polluted groundwater was close to two decades; however, more researches were still required to provide sufficient information of reactive mechanisms about combined pollution of heavy metals and organic matter and predict long-term performance of PRBs[8-10]. The purpose of this paper is to evaluate the efficiency of iron pillar towards $\mathrm{Cr}(\mathrm{VI})$ and TCE removal, evaluate the sorts of elements on the iron surface through Scanning Electron Microscopy (SEM) and Energy-Dispersive Spectrometry (EDS).

\section{Materials and Methods}

The organic glass pillar, water tanks and peristaltic pump were used as experimental apparatus (Fig. 1). The height of the pillar was $60 \mathrm{~cm}$, and the diameter of the pillar was $8 \mathrm{~cm}$. Quartz sand of 2 $\mathrm{cm}$ thick was laid on the bottom of the pillar, and iron powder was filled on the quartz sand with a certain set of water space at the head of the pillar. On the side of the pillar five sampling ports were set, and the distance between two sampling ports was $10 \mathrm{~cm}$. Sampling ports were closed with rubber stoppers, and syringes tied to the rubber stoppers were used to take samples. Polluted ground water 
containing $\mathrm{Cr}(\mathrm{VI})$ and TCE were lifted by peristaltic pump from the bottom to the up of the pillar from the influent water tank with $10 \mathrm{ml} / \mathrm{min}$ of flow velocity. The running time of the pillar was $200 \mathrm{~d}$ at room temperature. About 40 mesh of iron powder with purity of $98.5 \%$ was used as reducing agent to remove $\mathrm{Cr}(\mathrm{VI})$ and TCE. and the impurities of iron powder are $\mathrm{Mn}(\leq 0.30 \%), \mathrm{Si}(\leq 0.11 \%), \mathrm{C}(\leq 0.02 \%)$ and $\mathrm{S}(\leq 0.02 \%)$. The compositions of the experimental water were clean groundwater adding $10 \mathrm{mg} / \mathrm{L}$ of $\mathrm{Cr}$ (VI) and $5 \mathrm{mg} / \mathrm{L}$ of TCE.Experimental instruments included atomic absorption spectrophotometer(TAS-990 Super),Gas chromatography(Agilent 6890N),Roman spectrum(Invia 2000) and Scanning electron microscope (HITACHI).Acetylene-air flame atomic absorption spectrometry was used to measure Cr(VI), gas chromatography was used to measure TCE and SEM, EDS and Roman spectrum were used to analysis iron powder surface.



Fig. 1 Experimental apparatus

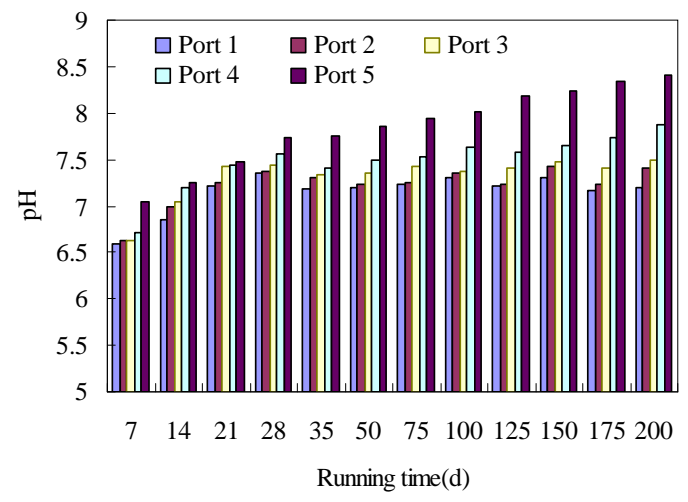

Fig. $2 \mathrm{pH}$ change with running time

\section{Results and discussion}

\section{Change of $\mathrm{pH}$}

In order to study $\mathrm{pH}$ change with running time $\mathrm{pH}$ of each sampling port was measured at regular intervals. From the bottom of the pillar sampling ports were sequence numbered Port 1, Port 2, Port 3, Port 4 and Port 5. The test results of $\mathrm{pH}$ are shown in Fig. 2. During operation of 28 days, $\mathrm{pH}$ of all sampling ports increased significantly. After 28 days, $\mathrm{pH}$ of Port 5 remained fast rising trend, $\mathrm{pH}$ of Port 4 increased slowly and $\mathrm{pH}$ of other ports changed little. The reaction between $\mathrm{Fe}(0)$ and chlorinated organic compounds $(\mathrm{RCl})$ is based on the following equation[19]: $\mathrm{Fe}^{0}+\mathrm{RCl}+\mathrm{H}^{+} \rightarrow \mathrm{Fe}^{2+}+$ $\mathrm{RH}+\mathrm{Cl}^{-}$. In this reaction process hydrogen ions are consumed. The reaction of $\mathrm{Fe}(0)$ and $\mathrm{Cr}(\mathrm{VI})$ is base on the following equation[20]: $\mathrm{Cr}_{2} \mathrm{O}_{7}{ }^{2-}+2 \mathrm{Fe}^{0}+7 \mathrm{H}_{2} \mathrm{O} \rightarrow 2 \mathrm{Cr}^{3+}+14 \mathrm{OH}^{-}+2 \mathrm{Fe}^{3+}$. In this process hydroxyl ions are produced. Therefore, removal of TCE and $\mathrm{Cr}(\mathrm{VI})$ using $\mathrm{Fe}(0)$ making $\mathrm{pH}$ rise. Before 28 days $\mathrm{pH}$ increased quickly, because passivation membrane had not formed on the iron surface, and reaction rate was fast. After 28 days, some iron reactive products formed at the bottom of the pillar, covered the surface of iron, and decreased the reaction rate. Hence $\mathrm{pH}$ of sampling ports of bottom had not obvious change but $\mathrm{pH}$ of the upper ports still rose.

Changes of TCE and $\mathrm{Cr}(\mathrm{VI})$ concentration

To study TCE concentration changed over time under Long-term operation the daily average concentration of effluent TCE were measured. The curves of TCE concentration and removal rate are shown in Fig.3. As the running time changed from 7 day to 200 day, effluent TCE concentration increased, and TCE removal rate decreased. The effluent TCE concentration changed from $0.26 \mathrm{mgL}$ to $0.74 \mathrm{mgL}$, accordingly, TCE removal rate changed from $94.8 \%$ to $85.2 \%$. According the reaction between $\mathrm{Fe}^{0}$ and $\mathrm{TCE}\left(\mathrm{Fe}^{0}+\mathrm{RCl}+\mathrm{H}^{+} \rightarrow \mathrm{Fe}^{2+}+\mathrm{RH}+\mathrm{Cl}^{-}\right)$there were not precipitations generating. But due to the presence of $\mathrm{Cr}(\mathrm{VI})$ in the pillar, reaction between $\mathrm{Fe}^{0}$ and $\mathrm{Cr}(\mathrm{VI})$ generated some iron oxides that inhibited the reaction of $\mathrm{Fe}^{0}$ with TCE. Therefore effluent TCE concentration decreased consequently. But TCE removal rate was still $80 \%$ above, the life of the iron was sustainable. 
In order to study $\mathrm{Cr}(\mathrm{VI})$ concentration changed with time under long-term operation the daily average concentration of effluent $\mathrm{Cr}(\mathrm{VI})$ were measure at regular intervals. The curves of $\mathrm{Cr}(\mathrm{VI})$ concentration and removal rate are shown in Fig. 4. In the whole operating process, the effluent $\mathrm{Cr}(\mathrm{VI})$ concentration increased and $\mathrm{Cr}(\mathrm{VI})$ removal rate declined continually. During 200 day of running the effluent $\mathrm{Cr}(\mathrm{VI})$ concentration varied from $0.36 \mathrm{mgL}$ to $1.74 \mathrm{mgL}$, accordingly, $\mathrm{Cr}(\mathrm{VI})$ removal rate changed from $96.4 \%$ to $82.6 \%$.


Fig. 3 TCE removal with running time

Fig. $4 \mathrm{Cr}(\mathrm{VI})$ removal with running time

SEM pictures of iron surface

The products attached to the iron powder surface have important effects on the reaction of iron and the pollutants. For qualitatively checking the iron powder surface before and after iron pillar running, iron powder were investigated by SEM. Fig. 5(a) is the raw iron powder pictures of different magnification before reaction. The raw iron powder surface is smooth, and has rich holes without mulches. After 200 day running the iron powder surface is covered large area of the materials and the original holes are not clearly to be seen(Fig. 5(b)). This is the reason why reaction rate reduced at the end of running.



(a) Raw iron (Magnification of 500 and 5000)

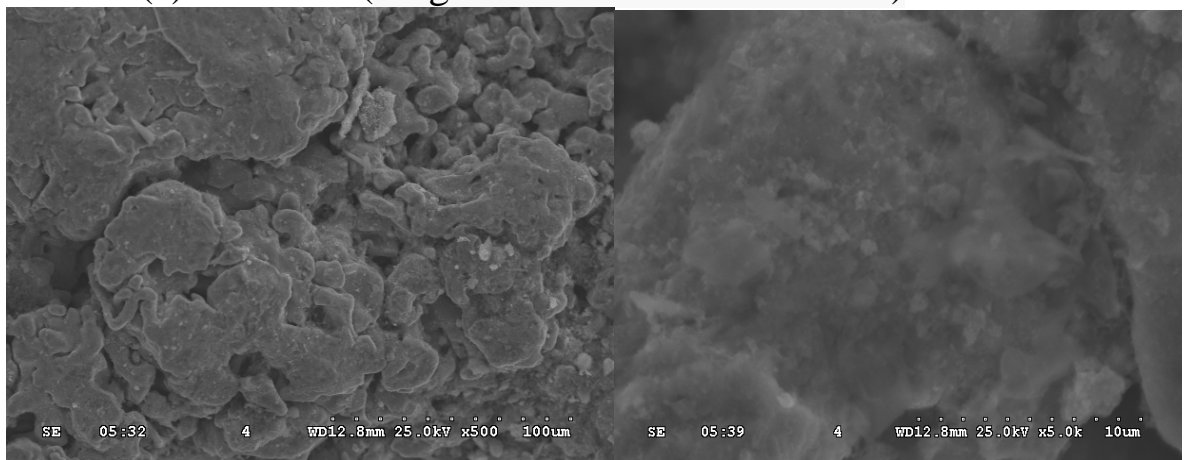

(b) Iron of 200d running (Magnification of 500 and 5000)

Fig. 5 Iron images of SEM 
EDS detection of iron surface

In order to determine what are the elements on the iron powder surface and how much of their content, iron powder surface was detected with EDS at the end of pillar running, and EDS results are shown in Fig. 6. Fig. 6(1) shows the scanning zone of iron powder and Fig. 6(2) shows the elements spectra. From Fig. 6 we can see the iron powder surface contained the elements of carbon, oxygen, silicon, calcium, chromium and iron. Among them sources of silicon were impurities of the iron or sand from the bottom of the columns, and carbon and calcium come from influent. Oxygen and chromium come from potassium dichromate of influent. These elements of weight contents were sorted from high to low: iron (6.44\%), oxygen(19.86\%), carbon(6.20\%), calcium(4.56\%), $\operatorname{silicon}(0.58 \%)$ and chromium $(0.35 \%)$.

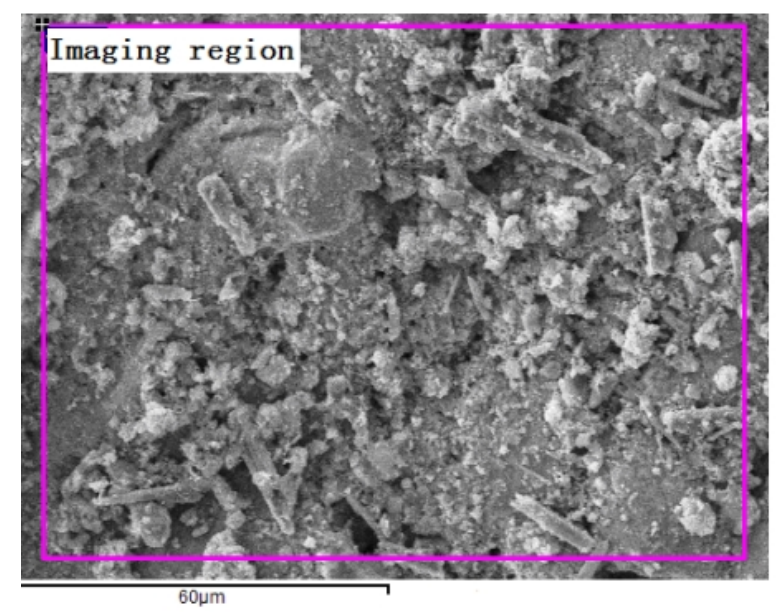

(a) Scanning zone



(b) Peak figure of the elements

Fig. 6 EDS images

\section{Conclusions}

Iron powder could effectively remove mixed pollution of $\mathrm{Cr}(\mathrm{VI})$ and TCE in the groundwater, The removal rate of $\mathrm{Cr}(\mathrm{VI})$ and TCE all reached $80 \%$ above with $200 \mathrm{~d}$ of iron pillar running. The reactions between iron and $\mathrm{Cr}(\mathrm{VI})$ or TCE consumed hydrogen ion, so effluent $\mathrm{pH}$ increased from the original of 7.05 to the end of 8.41 with running time increase. After reaction with $\mathrm{Cr}(\mathrm{VI})$ and TCE the elements producing on the surface of the iron powder were iron ,oxygen, carbon, calcium, silicon and chromium and the iron content was the largest than others.

\section{Acknowledgements}

This work was financially supported by the National Natural Science Foundation of China (51308274).

\section{References}

[1] Mackay D. M.,Cherry J. A. : Environ. Sci. Technol. Vol.23(1989), p. 630-636.

[2] Higgins M. R., Olson T. M. : Environ. Sci. Technol. Vol.43(2009), p. 9432-9438.

[3] Barrera-Díaz C. E.,Lugo-Lugo V.,Bilyeu B. : J. Hazard. Mater. Vol.223(2012), p. 1-12.

[4] Obiri-Nyarko F.,Grajales-Mesa S. J.,Malina G. : Chemosphere. Vol.111(2014), p. 243-259.

[5] Fu F, Dionysiou D D,Liu H. : J. Hazard. Mater. Vol.267(2014), p. 194-205.

[6] Nakano Y.,Hua L. Q., Nishijima W.,Shoto E.,Okada M. : Water Res. Vol.34(2000), p. 4139-4142.

[7] Arora M.,Snape I., Stevens G.W.: Cold Reg. Sci. Technol. Vol.69(2011), p. 59-63.

[8] Henderson A. D., Demond A. H.: Environ.Eng. Sci. Vol.24(2007), p. 401-423. 
[9] Gheju M. : Water, Air, Soil Pollut. Vol.222(2011), p.103-148.

[10] Song T.,Gao Y. :Desalin. Water Treat. Vol. 52(2014), p. 5990-5994. 